\title{
Neural and Cancer Stem Cells in Tumor Suppressor Mouse Models of Malignant Astrocytoma
}

\author{
S. Alcantara Llaguno, J. Chen, C.-H. Kwon, and L.F. Parada \\ Department of Developmental Biology, The University of Texas Southwestern Medical Center, Dallas, Texas 75390
}

\begin{abstract}
Malignant astrocytomas are highly invasive brain tumors that portend poor prognosis and dismal survival. Mouse models that genetically resemble the human malignancy provide insight into the nature and pathogenesis of these cancers. We previously reported tumor suppressor mouse models based on conditional inactivation of human astrocytoma-relevant genes $p 53, N f 1$, and Pten. These mice develop, with full penetrance, varying grades of astrocytic malignancy that recapitulate the human condition histologically and molecularly. Our studies indicate a central role for neural stem cells and stem-cell-like cancer cells in tumor initiation and progression. These mouse models thus represent powerful tools for investigating various aspects of tumor development that otherwise cannot be explored in humans. Further studies will provide a better understanding of the biology of these tumors and will hopefully pave the way for more effective therapeutic approaches for these devastating diseases.
\end{abstract}

Gliomas are the most common primary intracranial neoplasms in both pediatric and adult populations. The most malignant form, glioblastoma multiforme (GBM), is the most prevalent and also the most lethal, with a median survival of less than 1 year (Maher et al. 2001; Zhu and Parada 2002). Despite numerous advances in the field, however, these tumors remain resistant to conventional therapies and portend dismal outcomes for patients (Stupp et al. 2005).

Gliomas are classified on the basis of predominant tumor cell type(s), and astrocytomas, which morphologically resemble astrocytes, comprise the majority of these tumors. These tumors exhibit cellular heterogeneity and extensive infiltration into adjacent normal structures, which precludes complete surgical resection. Radiotherapy and chemotherapy improve survival but are not curative (Maher et al. 2001; Zhu and Parada 2002).

Astrocytic tumors are further classified on the basis of histopathologic and clinical criteria into increasing degrees of malignancy: grades I through IV. Grade I tumors are benign, whereas grade II tumors are low-grade malignancies that undergo early diffuse infiltration, rendering them surgically incurable. Grade III (anaplastic) and grade IV (GBM) astrocytomas are highly malignant and invasive tumors that are lethal within years to months. GBMs can be further subtyped as secondary GBMs, with previous clinical history of a lower-grade lesion, whereas primary GBMs arise de novo. Unlike other malignancies, high-grade astrocytomas rarely metastasize outside the central nervous system (CNS); hence, tumor grade serves as the primary determinant of clinical outcome (Maher et al. 2001; Furnari et al. 2007).

At the molecular level, a variety of mutations have been described in human astrocytomas. The classical genetic alterations target pathways involved in cell cycle and apoptosis regulation, such as P53, INK4A,CDK4, and $R B$, as well as growth factor signaling through $E G F$, $P D G F, P T E N$, and NF1. Frequent mutations in these genes underscore the importance of mitogenic signaling through receptor tyrosine kinases coupled with inactivation of critical negative regulators of cell proliferation and senescence in the pathogenesis of these tumors ( $\mathrm{Zhu}$ and Parada 2002; Louis 2006; Furnari et al. 2007).

\section{NEURAL STEM CELLS IN DEVELOPMENT AND CANCER}

Neural stem cells are self-renewing cells in the CNS that exhibit multipotent differentiation into all neural cell types in the brain, including neurons, astrocytes, and oligodendrocytes (Gage 2000). In the adult mammalian brain, the two major neural stem cell niches are the subventricular zone (SVZ) of the lateral ventricle and the subgranular layer of the dentate gyrus. The type-B neural stem cells in the SVZ give rise to type-C transient amplifying cells which then give rise to neuroblasts that migrate along a defined pathway, called the rostral migratory stream (RMS), and into the olfactory bulb (OB), where they differentiate into mature neurons (Doetsch et al. 1999; Alvarez-Buylla and Lim 2004). In the dentate gyrus, neurogenesis also occurs in the subgranular zone (SGZ), which produces local neurons that incorporate into the granule cell layer (Zhao et al. 2008).

Some cancer cells share important characteristics exhibited by stem cells, including unlimited replicative potential, diversity of progeny, telomere maintenance, and migratory properties (Sanai et al. 2005). In contrast to cancer cells, however, the function of stem cells at different stages of development is tightly regulated by diverse signaling pathways that impinge on various processes, including self-renewal, differentiation, and survival (Reya et al. 2001; Vescovi et al. 2006; Dalerba et al. 2007). Hence, it has been hypothesized that this population of undifferentiated cells that persist throughout the lifetime of an individual may have important roles in the natural progression of cancer.

Historically, the differentiated astrocyte has been thought to be the cell of origin of astrocytomas (Sanson et 
al. 2004; Sanai et al. 2005). On the other hand, numerous studies have suggested that these tumors may arise from the transformation of neural precursor cells (Holland et al. 2000 ) or dedifferentiation of mature astrocytes (Bachoo et al. 2002; Uhrbom et al. 2002). None of these studies have been conclusive so far. Given the recent in vivo identification of these progenitor populations in the adult brain, a previously thought of postmitotic organ, the proposal that neural stem cells can give rise to these tumors is an attractive hypothesis, but one that has yet to be experimentally verified.

Cancer cells with stem cell properties have been isolated from human cancers. These "cancer stem cells" have been operationally defined as a subpopulation of cells within tumors that maintain the self-renewing or propagating properties that confer the ability to initiate tumor formation in immunodeficient mice (Dalerba et al. 2007). These cells are thought to be responsible for the aggressive behavior, invasiveness, metastatic potential, and even resistance to conventional chemotherapy and radiotherapy of many tumors (Reya et al. 2001; Wang and Dick 2005; Dalerba et al. 2007). In human astrocytomas, the presence of stem-like cancer cells has been reported, and it has been suggested that the $\mathrm{CD} 133^{+}$fraction of GBMs comprise the population of self-renewing stem-like cancer cells with enriched tumorigenic capacity (Singh et al. 2004). These cancer stem cells have also been shown to be sensitive to bone morphogenetic protein signaling inhibition while being resistant to radiation therapy (Bao et al. 2006; Piccirillo et al. 2006; Lee et al. 2008). Many questions remain, however, as the molecular mechanisms that regulate cancer and normal neural stem cell behavior are still being unraveled, and efforts are under way to exploit these cells as possible therapeutic targets.

\section{TUMOR SUPPRESSORS IN NEURAL STEM CELL AND CANCER DEVELOPMENT}

Various tumor suppressors have been implicated in cancer, and Nf1, p53, and Pten represent tumor suppressor pathways that are frequently involved in human malignant astrocytomas. In fact, these three tumor suppressors are among the most frequently mutated genes in sporadic human GBM (TCGA GBM Disease Working Group; http://cancergenome.nih.gov/dataportal/). Nf1 encodes neurofibromin, a GTPase-activating protein that negatively regulates Ras, a downstream effector of receptor tyrosine kinase signaling (Le and Parada 2007). By virtue of epidermal growth factor receptor (EGFR) amplification and platelet-derived growth factor (PDGF) receptor overexpression, Ras signaling is hyperactivated (although Ras mutations are infrequent) in sporadic GBMs (Zhu and Parada 2002). On the other hand, p53, involved in apoptosis, cell cycle arrest, and DNA-damage repair, is frequently mutated early on in low- and highgrade astrocytomas, whereas mutations in Pten, which negatively regulates the phosphoinositide-3'-kinase (PI3K)-Akt signaling involved in cell proliferation, survival, and migration, are frequently found in high-grade astrocytomas (Furnari et al. 2007). Consistent with the above findings, individuals with germ-line mutations in p53 (Li Fraumeni), Nf1 (neurofibromatosis type 1), and Pten (Cowden disease) have increased incidence of developing astrocytomas compared to the general population (Rasmussen et al. 2001; Gutmann et al. 2002; Ichimura et al. 2004). These data underscore a central role for these tumor suppressors in the development of malignant astrocytomas.

Interestingly, Nf1, p53, and Pten, like other tumor suppressors, have lately been shown to function as negative regulators of neural stem cell function. $N f 1$ deficiency was shown to promote neural stem cell proliferation and survival (Dasgupta and Gutmann 2005; Hegedus et al. 2007). Loss of $p 53$ increases proliferation in the SVZ neural stem/progenitors and provides a growth advantage compared to wild-type cells (Gil-Perotin et al. 2006; Meletis et al. 2006), and Pten loss increases neural stem cell proliferation and self-renewal (Groszer et al. 2001, 2006).

\section{MOUSE MODELS OF MALIGNANT ASTROCYTOMA}

Signature genetic lesions found in human tumors have been exploited in the mouse to generate genetically engineered animal models that have greatly enhanced our understanding of astrocytoma development. Strategies have included gain-of-function approaches, such as overexpression of active forms of Ras, Akt, EGFR, PDGF, and transforming antigens $\mathrm{v}-s r c$ and polyomavirus middle $\mathrm{T}$ antigen, often in combination with targeted deletions of Ink4A/Arf or Pten (Weissenberger et al. 1997; Holland et al. 2000; Ding et al. 2001; Bachoo et al. 2002; Uhrbom et al. 2002; Xiao et al. 2002; Fomchenko and Holland 2006; Furnari et al. 2007). These mutations were induced in the germ line or in specific cell populations, and tumor development was observed with variable penetrance. The first endogenous genetic tumor suppressor mouse model was based on heterozygous mice carrying cis germ-line mutations in $N f 1$ and $p 53$. These mice developed high-grade astrocytomas with varying penetrance depending on genetic background (Reilly et al. 2000).

\section{TUMOR SUPPRESSOR MOUSE MODELS: DISSECTING THE ROLE OF NEURAL AND CANCER STEM CELLS}

To better understand the biology of malignant astrocytomas, our lab previously developed mouse models based on tumor suppressor inactivation in specific cell types in the brain. We used Cre-loxP technology that permits more selective spatial and temporal ablation of tumor suppressors. We took advantage of a mouse transgenic expressing Cre recombinase under the control of the $h G F A P$ promoter (hGFAP-Cre) (Zhuo et al. 2001) and combinations of tumor suppressor conditional alleles or germ-line mutations (Jacks et al. 1994; Groszer et al. 2001; Zhu et al. 2001; Lin et al. 2004). We first generated conditional mutant mice wherein cis heterozygous germ-line or somatic $p 53$ heterozygosity was combined with somatic Nfl heterozygosity driven by a Cre recombinase that is active in both neural stem cells and differentiated astrocytes (Zhu et al. 2005). These mice developed astrocy- 
tomas with $100 \%$ penetrance and were indistinguishable from the human malignancy based on known histologic and molecular criteria. This provided evidence that $N f 1$ and p53 loss of function is sufficient to initiate malignant astrocytoma formation. Variations in the genetic configurations of the tumor suppressor alleles also showed that p53 inactivation concomitant or before $N f 1$ inactivation is critical for tumor development. These are shown in Table 1 as Mut 1 or Mut3 conditional mutant mice, which developed, with $100 \%$ penetrance, a spectrum of low- to highgrade malignant astrocytomas, whereas Mut2 mutants very rarely developed tumors.

In an additional refinement, when we added somatic Pten heterozygosity to the Nf1-p53 mouse models, mutant mice (Mut4 and Mut6) were found to develop high-grade astrocytomas (Table 1) with decreased latency of tumor formation (Kwon et al. 2008). We also found that NfI and Pten somatic heterozygosity alone was not sufficient for astrocytoma development (Mut0). This crucial role of $p 53$ in tumor initiation is consistent with the frequency of $p 53$ mutations observed in low-grade astrocytomas. These studies underscore the importance of the $N f 1, p 53$, and Pten tumor suppressors in malignant astrocytoma formation and progression.

\section{NEURAL STEM/PROGENITORS AS CANCER-INITIATING CELLS}

Studies from these tumor-bearing mice show considerable evidence for the role of neural stem cells in the development of malignant astrocytomas. Analysis of conditional mutant mice at different stages of tumor development showed the earliest lesions in the neurogenic niche of the adult SVZ (Zhu et al. 2005). Presymptomatic mutant mice at young ages are histologically similar to littermate controls (Fig. 1). However, as these mutant mice aged further, we observed areas of hyperplasia as shown by hematoxylin and eosin (H\&E) staining and confirmed by immunohistochemistry. A short-term pulse with bromodeoxyuridine (BrdU) showed an increase in proliferating cells in the SVZ, as compared to controls (Fig. 1). Longer-term pulses with BrdU in presymptomatic mutant mice uncovered migration defects, such that more $\mathrm{BrdU}^{+}$cells could be seen outside the SVZ (Kwon et al. 2008). Older mice subsequently developed tumors, the majority in areas near the SVZ, starting at 4 months of age (Zhu et al. 2005). Moreover, we found growth changes using neurosphere cultures of SVZ cells isolated from presymptomatic young mice (data not shown). These data demonstrate that neural stem/progenitors show proliferation and migration defects before tumor formation, suggesting that these cells may be the cancer-initiating cells in our tumor suppressor mouse models.

The hypothesis that neural stem cells may be the cell of origin of astrocytomas is illustrated in Figure 2. We propose that tumor-initiating mutations target the reservoir of self-renewing stem cells, allowing for the accumulation of more mutations required for malignant transformation. The tumorigenic phenotype may manifest itself in dividing progenitor-like cells, which undergo deregulated cell divisions to create the tumor bulk. Other mechanistic scenarios may also be possible, given a different set of initiating mutations or environmental influences.

Direct examination of the role of neural stem/progenitors as the origin of these tumors will require directly targeting these cells for tumor suppressor inactivation. Whether more mature, differentiated CNS cells have the capacity to give rise to these tumors will also need to be addressed. This will require the use of more cell-typespecific promoters to drive Cre-mediated recombination. Cell ablation or depletion experiments will also determine whether these cells are required for tumor development.

Identification of the cell of origin will be crucial for investigating the various mechanisms of tumor initiation and progression. Susceptible cells for transformation can be targeted with genetic lesions found in human patients to discover other tumor-initiating mutations and determine cooperation among these genes in astrocytoma development. Identifying these cells will also allow mechanistic studies on signal transduction pathways involved early on during tumor development.

\section{CANCER STEM CELLS IN MOUSE MODELS OF MALIGNANT ASTROCYTOMA}

Malignant astrocytomas are very heterogeneous tumors. Although malignancies are predominantly astrocytic in character, a variety of tumor cell types can be seen in the tumor bulk, as shown by immunostaining (Fig. 3). Some tumor cells were found to express primitive neural stem/progenitor markers such as nestin. Other tumor cells were immunoreactive for markers of more differentiated

Table 1. Genetic configurations and phenotypes of Nf1-p53-Pten tumor suppressor mouse models

\begin{tabular}{|c|c|c|c|c|c|}
\hline Mutant & Cre & $N f 1$ & $p 53$ & Pten $^{\mathrm{a}}$ & Tumor grade ${ }^{\mathrm{a}}$ \\
\hline Mut0 & hGfap-Cre & $N f 1^{f /+}$ & $p 53^{+/+}$ & Pten $^{f /+}$ & no tumors \\
\hline Mut1 & hGfap-Cre & $N f 1^{f / f}$ & $p 53^{-/-}$ & Pten $^{+/+}$ & low- to high-grade astrocytomas \\
\hline Mut2 & hGfap-Cre & $N f f^{f / f}$ & $p 53^{-/+}$ & Pten $^{+/+}$ & very rare high-grade astrocytomas \\
\hline Mut3 & hGfap-Cre & $N f 1^{f /+}$ & $p 53^{-/+}$ & $\mathrm{Pten}^{+/+}$ & low- to high-grade astrocytomas \\
\hline Mut4 & hGfap-Cre & $N f 1^{f /+}$ & $p 53^{-/+}$ & Pten $^{f /+}$ & high-grade astrocytomas \\
\hline Mut5 & hGfap-Cre & $N f 1^{f /+}$ & $p 53^{-/ f}$ & Pten $^{+/+}$ & low- to high-grade astrocytomas \\
\hline Mut6 & hGfap-Cre & $N f 1^{f /+}$ & $p 53^{-/ f}$ & Pten $^{f /+}$ & high-grade astrocytomas \\
\hline
\end{tabular}

Data from Zhu et al. (2005) and Kwon et al. (2008).

$f$ indicates flox/loxP; + indicates wild type.

${ }^{\mathrm{a}} \mathrm{Low}$ grade $=$ grade II; high grade $=$ grade III or grade IV astrocytomas . 

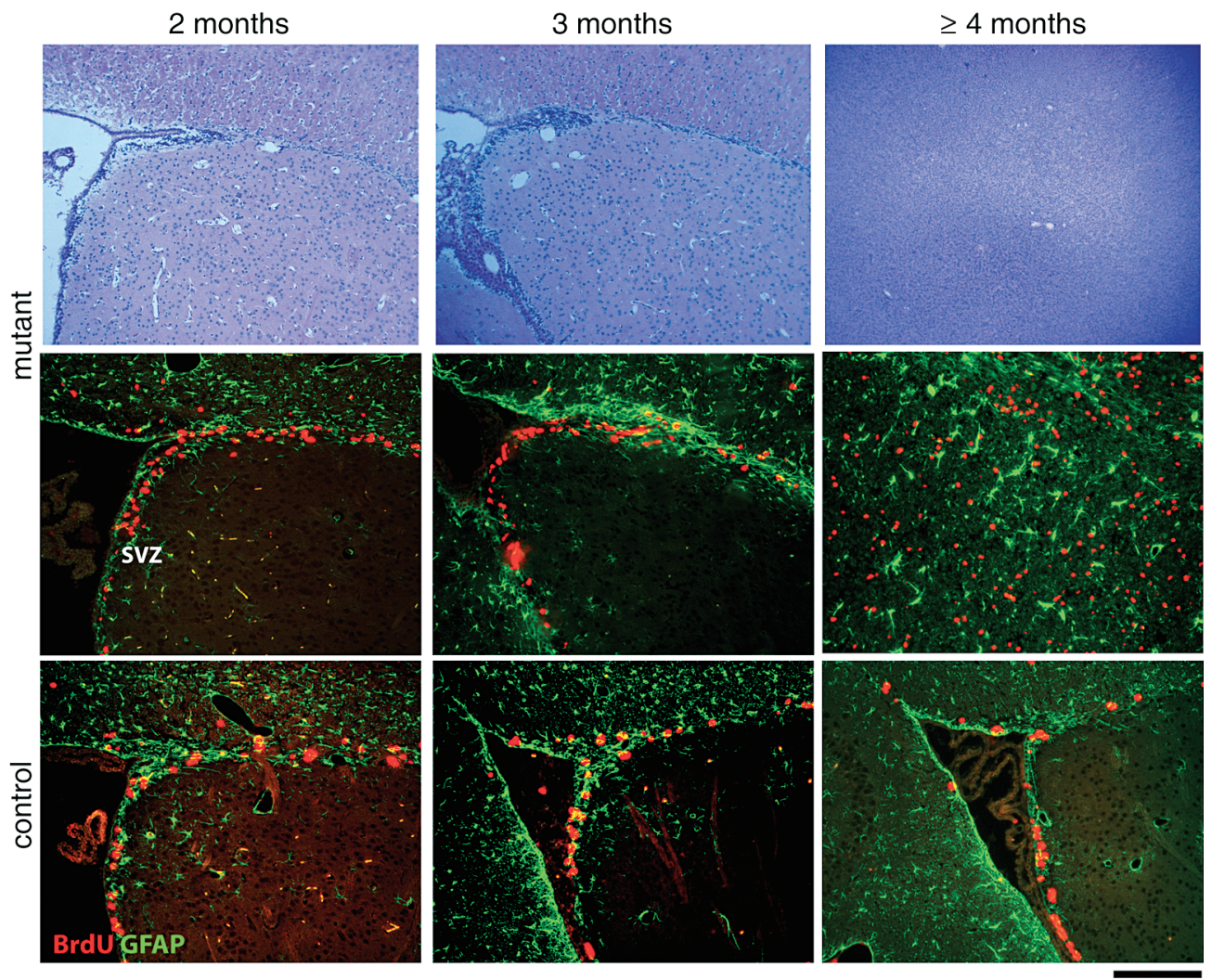

Figure 1. Tumor suppressor mouse models show early hyperplastic lesions in the SVZ. Time course analysis of Mut3 (hGFAP-Cre; $N f 1^{f l o x /+} ; p 53^{-/+}$) conditional mutant mice at 2,3 , and 4 months of age shows progressive changes in the SVZ. H\&E staining shows increased cellularity in the SVZ by as early as 3 months of age in mutant mice. Short-term (1-hour) BrdU pulsing in these mice indicates an increase in proliferating $\mathrm{BrdU}^{+}$, as well as in $\mathrm{GFAP}^{+}$cells in the SVZ before full-blown tumor formation. Controls show a decrease in $\mathrm{BrdU}^{+}$proliferating cells with age. Bar, $200 \mu \mathrm{m}$.

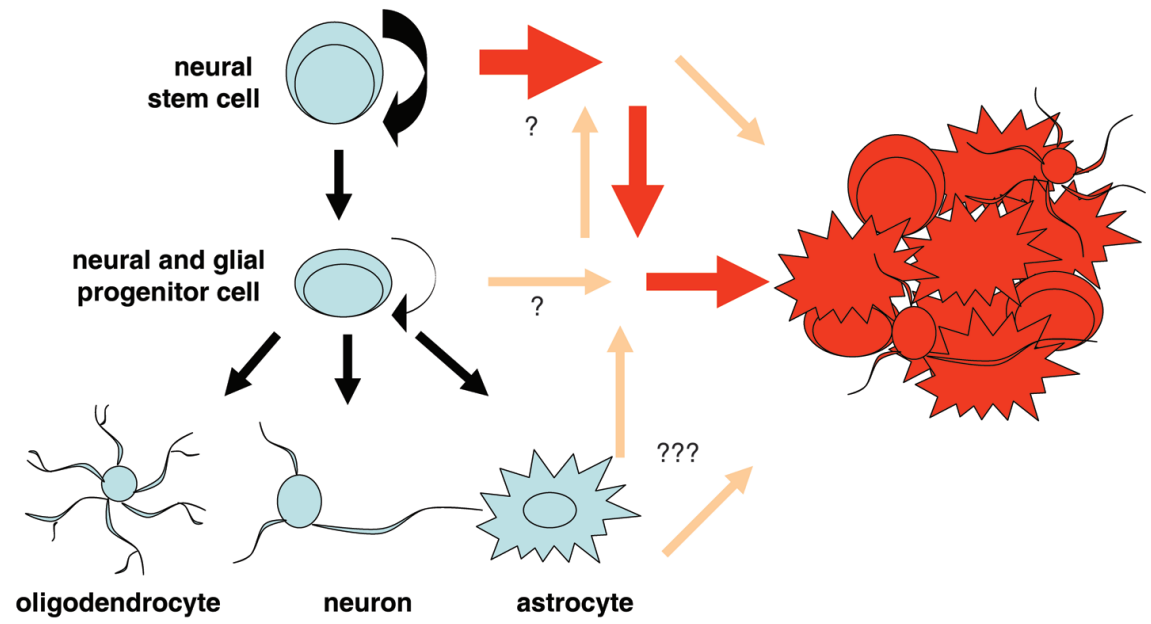

Figure 2. Cell of origin hypothesis of malignant astrocytomas. A neural stem cell origin of malignant astrocytomas proposes the lifelong self-renewing stem cells, as opposed to progenitor cells with limited self-renewal or differentiated astrocytes, as the path of least resistance to tumorigenesis. These neural stem cells may transform into dividing progenitor-like cells that undergo uncontrollable mitoses and give rise to tumors (red arrows). Alternative pathways, such as dedifferentiation of the more mature cell types into stemor progenitor-like cells (light orange arrows), are also shown. 

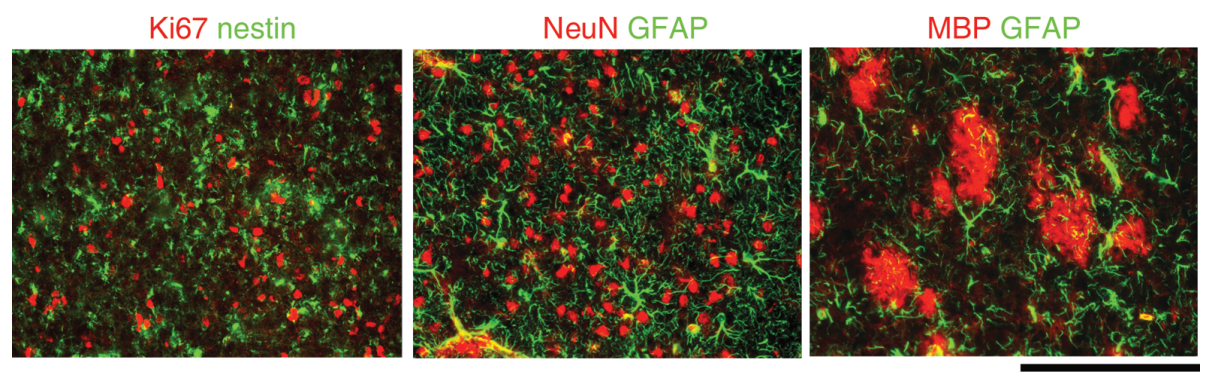

Figure 3. Tumor suppressor mouse models show the presence of cancer cells expressing markers of immature and multilineage differentiation. Full blown mouse tumors show heterogeneity in tumor cell composition, expressing markers of undifferentiated cells, such as nestin, and more mature astrocytic (Gfap), neuronal (NeuN), and oligodendrocytic (MBP) differentiation. Bar, $200 \mu \mathrm{m}$.

CNS cell types, including the astrocytic marker glial fibrillary acidic protein (GFAP), neuronal marker NeuN, and oligodendrocytic marker myelin basic protein (MBP), suggesting the capacity for multilineage differentiation (Fig. 3). These tumors can also give rise to self-renewing neurosphere-forming cells when cultured in serum-free media, similar to normal neural stem cell cultures (data not shown). These data suggest that a subpopulation of tumor cells may exhibit more stem-cell-like properties compared to the rest of the tumor bulk.

The crucial experiment will be to determine whether this rare subpopulation of cells has increased tumorigenic potential compared to other tumor cell types in serial transplantation assays. Compared to human "cancer stem cells," the use of mouse tumor cells orthotopically transplanted into immunodeficient mice may provide a better platform to determine the frequency of these "tumor-initiating" cells because of less interference of complex human cell-mouse microenvironment issues.

Identification of this rare subpopulation of cells will allow us to compare the molecular mechanisms that are operative in "cancer stem cells" vis à vis other tumor cells and normal neural stem cells. Exploiting their differences will be vital in designing novel therapeutic agents against these very aggressive cancers.

\section{PERSPECTIVE}

The use of genetic mouse models in studying human disease has greatly facilitated our understanding of cancer. Using tumor suppressor mouse models, we have validated mutations in human malignant astrocytomas as bona fide tumor-initiating mutations that lead to fullblown tumor development. We have also uncovered cooperativity between these tumor-initiating genes. Detailed studies of these tumor-bearing mice have also led to a greater understanding of the role of neural and stem-like cancer cells in tumor initiation and progression.

Further advances in the fields of neurodevelopment and cancer biology will provide more sophisticated tools for studying these malignancies. The interface between human and mouse cancers will need to be more fully exploited in order to rapidly translate basic science knowledge into practical clinical applications. The hope is that a more integrated understanding of the molecular and phys- iological processes underlying this complex disease will provide us with the means of finally cracking open some of the many secrets of brain tumor formation, ultimately resulting in more targeted and effective therapies.

\section{ACKNOWLEDGMENTS}

The authors thank Linda McClellan, Shawna Kennedy, Steven McKinnon, Patsy Leake, and Alicia Deshaw for technical assistance, and Parada Lab members, especially Renee McKay, for helpful suggestions and discussion. This work is supported in part by the Children's Tumor Foundation Young Investigator Award to S.A.L., Basic Research Fellowships from American Brain Tumor Association (in memory of Daniel J. Martinelli and Geoffrey J. Cunningham) to C.-H.K., and by National Institutes of Health grant P50NS05260602 and American Cancer Society grant RP0408401 to L.F.P. L.F.P. is an American Cancer Society Research Professor.

\section{REFERENCES}

Alvarez-Buylla, A. and Lim, D.A. 2004. For the long run: Maintaining germinal niches in the adult brain. Neuron 41: 683-686.

Bachoo, R.M., Maher, E.A., Ligon, K.L., Sharpless, N.E., Chan, S.S., You, M.J., Tang, Y., DeFrances, J., Stover, E., Weissleder, R., Rowitch, D.H., Louis, D.N., and DePinho, R.A. 2002. Epidermal growth factor receptor and Ink4a/Arf: Convergent mechanisms governing terminal differentiation and transformation along the neural stem cell to astrocyte axis. Cancer Cell 1: 269-277.

Bao, S., Wu, Q., McLendon, R.E., Hao, Y., Shi, Q., Hjelmeland, A.B., Dewhirst, M.W., Bigner, D.D., and Rich, J.N. 2006. Glioma stem cells promote radioresistance by preferential activation of the DNA damage response. Nature 444: 756-760.

Dalerba, P., Cho, R.W., and Clarke, M.F. 2007. Cancer stem cells: Models and concepts. Annu. Rev. Med. 58: 267-284.

Dasgupta, B. and Gutmann, D.H. 2005. Neurofibromin regulates neural stem cell proliferation, survival, and astroglial differentiation in vitro and in vivo. J. Neurosci. 25: 5584-5594.

Ding, H., Roncari, L., Shannon, P., Wu, X., Lau, N., Karaskova, J., Gutmann, D.H., Squire, J.A., Nagy, A., and Guha, A. 2001. Astrocyte-specific expression of activated p21-ras results in malignant astrocytoma formation in a transgenic mouse model of human gliomas. Cancer Res. 61: 3826-3836.

Doetsch, F., Caille, I., Lim, D.A., Garcia-Verdugo, J.M., and Alvarez-Buylla, A. 1999. Subventricular zone astrocytes are neural stem cells in the adult mammalian brain. Cell 97: 703-716. 
Fomchenko, E.I. and Holland, E.C. 2006. Mouse models of brain tumors and their applications in preclinical trials. Clin. Cancer Res. 12: 5288-5297.

Furnari, F.B., Fenton, T., Bachoo, R.M., Mukasa, A., Stommel, J.M., Stegh, A., Hahn, W.C., Ligon, K.L., Louis, D.N., Brennan, C., Chin, L., DePinho, R.A., and Cavenee, W.K. 2007. Malignant astrocytic glioma: Genetics, biology, and paths to treatment. Genes Dev. 21: 2683-2710.

Gage, F.H. 2000. Mammalian neural stem cells. Science 287: $1433-1438$.

Gil-Perotin, S., Marin-Husstege, M., Li, J., Soriano-Navarro, M., Zindy, F., Roussel, M.F., Garcia-Verdugo, J.M., and Casaccia-Bonnefil, P. 2006. Loss of p53 induces changes in the behavior of subventricular zone cells: Implication for the genesis of glial tumors. J. Neurosci. 26: 1107-1116.

Groszer, M., Erickson, R., Scripture-Adams, D.D., Lesche, R., Trumpp, A., Zack, J.A., Kornblum, H.I., Liu, X., and Wu, H. 2001. Negative regulation of neural stem/progenitor cell proliferation by the Pten tumor suppressor gene in vivo. Science 294: 2186-2189.

Groszer, M., Erickson, R., Scripture-Adams, D.D., Dougherty, J.D., Le Belle, J., Zack, J.A., Geschwind, D.H., Liu, X., Kornblum, H.I., and Wu, H. 2006. PTEN negatively regulates neural stem cell self-renewal by modulating G0-G1 cell cycle entry. Proc. Natl. Acad. Sci. 103: 111-116.

Gutmann, D.H., Rasmussen, S.A., Wolkenstein, P., MacCollin, M.M., Guha, A., Inskip, P.D., North, K.N., Poyhonen, M., Birch, P.H., and Friedman, J.M. 2002. Gliomas presenting after age 10 in individuals with neurofibromatosis type 1 (NF1). Neurology 59: 759-761.

Hegedus, B., Dasgupta, B., Shin, J.E., Emnett, R.J., HartMahon, E.K., Elghazi, L., Bernal-Mizrachi, E., and Gutmann, D.H. 2007. Neurofibromatosis-1 regulates neuronal and glial cell differentiation from neuroglial progenitors in vivo by both cAMP- and Ras-dependent mechanisms. Cell Stem Cell 1: 443-457.

Holland, E.C., Celestino, J., Dai, C., Schaefer, L., Sawaya, R.E., and Fuller, G.N. 2000. Combined activation of Ras and Akt in neural progenitors induces glioblastoma formation in mice. Nat. Genet. 25: 55-57.

Ichimura, K., Ohgaki, H., Kleihues, P., and Collins, V.P. 2004 Molecular pathogenesis of astrocytic tumours. J. Neurooncol. 70: $137-160$

Jacks, T., Remington, L., Williams, B.O., Schmitt, E.M., Halachmi, S., Bronson, R.T., and Weinberg, R.A. 1994. Tumor spectrum analysis in p53-mutant mice. Curr. Biol. 4: 1-7.

Kwon, C.H., Zhao, D., Chen, J., Alcantara, S., Li, Y., Burns, D.K., Mason, R.P., Lee, E.Y., Wu, H., and Parada, L.F. 2008 Pten haploinsufficiency accelerates formation of high-grade astrocytomas. Cancer Res. 68: 3286-3294.

Le, L.Q. and Parada, L.F. 2007. Tumor microenvironment and neurofibromatosis type I: Connecting the GAPs. Oncogene 26: 4609-4616.

Lee, J., Son, M.J., Woolard, K., Donin, N.M., Li, A., Cheng, C.H., Kotliarova, S., Kotliarov, Y., Walling, J., Ahn, S., et al. 2008. Epigenetic-mediated dysfunction of the bone morphogenetic protein pathway inhibits differentiation of glioblastoma-initiating cells. Cancer Cell 13: 69-80.

Lin, S.C., Lee, K.F., Nikitin, A.Y., Hilsenbeck, S.G., Cardiff, R.D., Li, A., Kang, K.W., Frank, S.A., Lee, W.H., and Lee, E.Y. 2004. Somatic mutation of $\mathrm{p} 53$ leads to estrogen receptor $\alpha$-positive and -negative mouse mammary tumors with high frequency of metastasis. Cancer Res. 64: 3525-3532.

Louis, D.N. 2006. Molecular pathology of malignant gliomas. Annu. Rev. Pathol. 1: 97-117.

Maher, E.A., Furnari, F.B., Bachoo, R.M., Rowitch, D.H., Louis, D.N., Cavenee, W.K., and DePinho, R.A. 2001.
Malignant glioma: Genetics and biology of a grave matter. Genes Dev. 15: 1311-1333.

Meletis, K., Wirta, V., Hede, S.M., Nister, M., Lundeberg, J., and Frisen, J. 2006. p53 suppresses the self-renewal of adult neural stem cells. Development 133: 363-369.

Piccirillo, S.G., Reynolds, B.A., Zanetti, N., Lamorte, G., Binda, E., Broggi, G., Brem, H., Olivi, A., Dimeco, F., and Vescovi, A.L. 2006. Bone morphogenetic proteins inhibit the tumorigenic potential of human brain tumour-initiating cells. Nature 444: 761-765.

Rasmussen, S.A., Yang, Q., and Friedman, J.M. 2001. Mortality in neurofibromatosis 1: An analysis using U.S. death certificates. Am. J. Hum. Genet. 68: 1110-1118.

Reilly, K.M., Loisel, D.A., Bronson, R.T., McLaughlin, M.E., and Jacks, T. 2000. Nf1;Trp 53 mutant mice develop glioblastoma with evidence of strain-specific effects. Nat. Genet. 26: $109-113$.

Reya, T., Morrison, S.J., Clarke, M.F., and Weissman, I.L. 2001. Stem cells, cancer, and cancer stem cells. Nature 414: 105-111.

Sanai, N., Alvarez-Buylla, A., and Berger, M.S. 2005. Neural stem cells and the origin of gliomas. N. Engl. J. Med. 353: 811-822.

Sanson, M., Thillet, J., and Hoang-Xuan, K. 2004. Molecular changes in gliomas. Curr. Opin. Oncol. 16: 607-613.

Singh, S.K., Hawkins, C., Clarke, I.D., Squire, J.A., Bayani, J., Hide, T., Henkelman, R.M., Cusimano, M.D., and Dirks, P.B. 2004. Identification of human brain tumour initiating cells. Nature 432: 396-401.

Stupp, R., Mason, W.P., van den Bent, M.J., Weller, M., Fisher, B., Taphoorn, M.J., Belanger, K., Brandes, A.A., Marosi, C., Bogdahn, U., et al. 2005. Radiotherapy plus concomitant and adjuvant temozolomide for glioblastoma. N. Engl. J. Med. 352: $987-996$

Uhrbom, L., Dai, C., Celestino, J.C., Rosenblum, M.K., Fuller, G.N., and Holland, E.C. 2002. Ink4a-Arf loss cooperates with KRas activation in astrocytes and neural progenitors to generate glioblastomas of various morphologies depending on activated Akt. Cancer Res. 62: 5551-5558.

Vescovi, A.L., Galli, R., and Reynolds, B.A. 2006. Brain tumour stem cells. Nat. Rev. Cancer 6: 425-436.

Wang, J.C. and Dick, J.E. 2005. Cancer stem cells: Lessons from leukemia. Trends Cell Biol. 15: 494-501.

Weissenberger, J., Steinbach, J.P., Malin, G., Spada, S., Rulicke, T., and Aguzzi, A. 1997. Development and malignant progression of astrocytomas in GFAP-v-src transgenic mice. Oncogene 14: 2005-2013.

Xiao, A., Wu, H., Pandolfi, P.P., Louis, D.N., and Van Dyke, T. 2002. Astrocyte inactivation of the $\mathrm{pRb}$ pathway predisposes mice to malignant astrocytoma development that is accelerated by PTEN mutation. Cancer Cell 1: 157-168.

Zhao, C., Deng, W., and Gage, F.H. 2008. Mechanisms and functional implications of adult neurogenesis. Cell 132: 645-660.

Zhu, Y. and Parada, L.F. 2002. The molecular and genetic basis of neurological tumours. Nat. Rev. Cancer 2: 616-626.

Zhu, Y., Romero, M.I., Ghosh, P., Ye, Z., Charnay, P., Rushing, E.J., Marth, J.D., and Parada, L.F. 2001. Ablation of NF1 function in neurons induces abnormal development of cerebral cortex and reactive gliosis in the brain. Genes Dev. 15: 859-876.

Zhu, Y., Guignard, F., Zhao, D., Liu, L., Burns, D.K., Mason, R.P., Messing, A., and Parada, L.F. 2005. Early inactivation of p53 tumor suppressor gene cooperating with NF1 loss induces malignant astrocytoma. Cancer Cell 8: 119-130.

Zhuo, L., Theis, M., Alvarez-Maya, I., Brenner, M., Willecke, K., and Messing, A. 2001. hGFAP-cre transgenic mice for manipulation of glial and neuronal function in vivo. Genesis 31: $85-94$. 


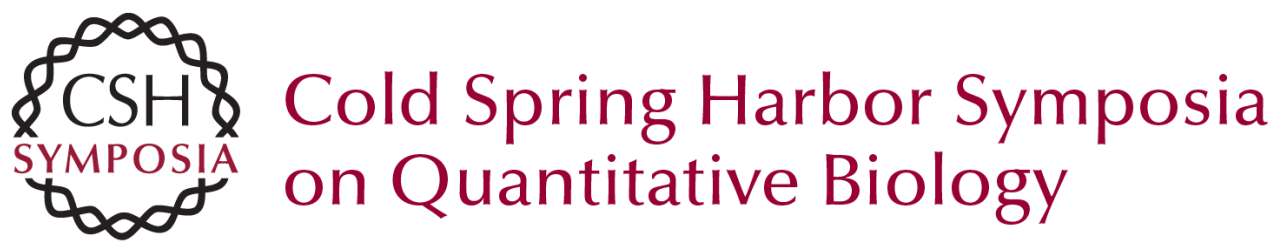

\section{Neural and Cancer Stem Cells in Tumor Suppressor Mouse Models of Malignant Astrocytoma}

S. Alcantara Llaguno, J. Chen, C.-H. Kwon, et al.

Cold Spring Harb Symp Quant Biol 2008 73: 421-426 originally published online November 6, 2008 Access the most recent version at doi:10.1101/sqb.2008.73.005

References This article cites 43 articles, 15 of which can be accessed free at: http://symposium.cshlp.org/content/73/421.full.html\#ref-list-1

\section{License}

Email Alerting Receive free email alerts when new articles cite this article - sign up in the Service box at the top right corner of the article or click here. 